\title{
THE ACCELERATION OF LINEAR FLOW IN THE DEEP VEINS OF THE LOWER EXTREMITY OF MAN BY LOCAL COMPRESSION ${ }^{1}$
}

\author{
By JOSEPH R. STANTON, EDWARD D. FREIS, AND ROBERT W. WILKINS \\ (From the Robert Rawson Evans Memorial, Massachusetts Memorial Hospitals, and the \\ Department of Medicine, Boston University School of Medicine, Boston, Mass.)
}

(Received for publication November 26, 1948)

\section{INTRODUCTION}

With the increasing age and life expectancy of the population (1) and the higher incidence of thromboembolic disease in older age groups (2-4) the problems of phlebothrombosis are becoming increasingly urgent. Particularly needed is more information concerning the etiology and pathologic physiology of venous thrombosis, so that adequate measures may be taken to prevent its consequences. The present communication presents the results of experiments upon one of the factors recognized as important in the formation of intravenous clots, namely, the velocity of venous flow.

In 1856, Virchow postulated that alterations of the blood current, of the blood chemistry and of the blood vessel wall, are factors important in the etiology of venous thrombosis (5). Since then numerous papers have been devoted to alterations of the vessel wall and of the blood chemistry and morphology but only scant and sporadic attention has been paid to changes in the venous current. It has been shown by careful pathological and roentgenographic studies that the deep venous system of the calf is the most important site of development of phlebothrombosis leading to pulmonary embolism (6-10). It has also been suspected that slowing of the venous current contributes to this situation (11-14). However, as yet, no one has related a slowing of flow to anatomic abnormalities in the deep veins of the leg nor has the effect of compression on the velocity of flow been previously reported. In this study particular attention was paid to the general form of the deep veins of the calf as well as to the velocity of flow and the effects of local compression.

\section{MATERIAL AND METHODS}

The subjects were a group of 12 male and eight female patients from the ward and private services of the Massa-

\footnotetext{
1 This investigation was supported in part by the Squibb Institute for Medical Research, New Brunswick, New Jersey.
}

chusetts Memorial Hospitals. Their ages ranged from 17 to 70 years. All subjects were studied after resting for 45 minutes in a quiet room the temperature of which was maintained relatively constant $\left( \pm 2^{\circ} \mathrm{C}\right.$. $)$.

With the patient supine upon the $\mathrm{X}$-ray table the entire lower extremity from the instep to the upper third of the thigh was encased in a series of loosely fitting blood pressure cuffs or in an inflatable legging (of a G-suit). The heel was elevated so that the calf was free of the table and the leg was immobilized by properly applied sandbags at the foot.

A 20 gauge, 11/2-inch needle was inserted through procainized skin into a distal vein on the dorsum of the foot in such a fashion that the tip of the needle was well within the pressurized area when the G-suit or cuffs were inflated. To the needle was attached a three-way stopcock and tubing leading to an infusion of normal saline solution which was allowed to flow at a constant slow rate for the purpose of keeping the needle patent between injections. All injections of test substances were made directly into the vein through the side arm of the three-way stopcock. After control observations were completed the limb was pressurized by inflating the garment or blood pressure cuffs at pressures of 20 or $35 \mathrm{~mm}$. $\mathrm{Hg}$, whereupon the test procedure was repeated.

In two patients an additional 18 gauge, two-inch needle was placed in the femoral vein just proximal to the upper margin of the inflatable garment. To this a five-inch segment of an $18 \mathrm{~F}$ nylon catheter was attached so that blood samples could be collected in oxalated tubes every four seconds. Three cc. of $0.5 \%$ Evans Blue Dye (T1824) were injected into the foot vein. Blood samples were then collected from the femoral vein for periods of 50 to 100 seconds. This procedure was carried out before and during the application of pressure as described above. The blood samples were centrifuged at 3,000 R.P.M. for 30 minutes and the supernatant plasma after appropriate dilution was analyzed for dye concentration using the Coleman photoelectric colorimeter. Thus, the appearance, maximum concentration, and disappearance of the dye in the femoral vein were accurately timed.

The test substances used in carrying out these experiments were solutions of 35\% Diodrast, $20 \%$ Decholin sodium, ${ }^{2}$ and $0.5 \%$ Evans Blue Dye $(\mathrm{T}-1824) .^{3}$ Diodrast was not given to patients with a history of allergy or previous diodrast reactions, and decholin was not administered in the presence or history of jaundice or liver

${ }^{2}$ Generously supplied by Mr. Charles Miles, Ames, Co., Elkhart, Indiana.

3W. G. Warner Co., New York, New York. 
disease. All injections were made by the same person who carefully timed the rate of injection. When discrepancies in the rate of injection occurred, the test was discarded or repeated. Stopwatches were calibrated to one-tenth of a second.

\section{RESULTS}

\section{A. Appearance time}

In the early phases of this investigation two independent observers noted through a fluoroscopic screen the time required for a $4 \mathrm{cc}$. dose of diodrast to pass from the needle to a lead marker applied to the upper third of the calf. The time from the start of injection until the dye reached the marker was noted and termed the appearance time. When the control observations were completed the limb was pressurized at $20 \mathrm{~m}$. $\mathrm{Hg}$ and then the procedure repeated.

Fifteen control observations were made in eight cases before the application of pressure and were compared with 11 observations made during pressurization of the limb at $20 \mathrm{~mm}$. $\mathrm{Hg}$. The control mean appearance time was 21.78 seconds as contrasted with a mean appearance time of 11.38 seconds during pressurization (Table I).

\section{B. Linear velocity of flow}

Because the method reported above was open to certain criticisms and also because in some instances the deep veins of the calf were poorly visualized during fluoroscopy, it seemed desirable to confirm these results, if possible by more accurate methods. To this end lead markers were fixed at specific intervals on calf and thigh and the distance between the markers carefully measured, so that the linear velocity in centimeters per second could be determined.

After observing fluoroscopically the appearance time of the diodrast in the calf and allowing $15 \mathrm{~min}$ utes for all the injected dye to be cleared from the veins, the dye was again administered and serial roentgenograms of the calf and thigh taken at exactly timed intervals during the period that diodrast would be expected to be in the field under study. Another pause was allowed for clearing, and the limb was then pressurized at $20 \mathrm{~mm}$. $\mathrm{Hg}$. Five minutes later the test was repeated and roentgenograms taken at exactly the same intervals as before. In three patients simultaneous control observations were made on the opposite extremity subjected to the same procedures as the experimental limb except that it was never pressurized.

As might be expected, technical difficulties including the exacting team work required, proper positioning of the limb, the absolute necessity for immobility of the subjects, and limitations imposed by the amount of X-ray to which any one patient might be safely exposed, prevented this technique from yielding results that could be accurately interpreted in every experiment. As a matter of fact, in several experiments a marked increase in velocity during pressurization resulted in the dye having already left the field by the time the thigh film was taken during pressurization. However, in no experiment could the results be interpreted as indicating that pressurization had decreased the velocity of venous flow. On the contrary, in practically every experiment, particularly when the

TABLE I

Effect of pressurization on the appearance time of $35 \%$ diodrast in the calf as visualized by fluoroscopy

\begin{tabular}{|c|c|c|c|c|c|c|c|c|}
\hline \multirow{2}{*}{ Patient } & \multirow{2}{*}{ Age } & \multicolumn{3}{|c|}{ Before pressurization } & \multicolumn{3}{|c|}{ During pressurization } & \multirow{2}{*}{$\begin{array}{c}\text { Per cent decrease } \\
\text { in mean } \\
\text { appearance } \\
\text { time during } \\
\text { pressurization }\end{array}$} \\
\hline & & $\begin{array}{c}\text { Number of } \\
\text { tests }\end{array}$ & Range & Mean & $\underset{\text { tests }}{\text { Number of }}$ & Range & Mean & \\
\hline $\begin{array}{l}\text { J. C. } \\
\text { Z. I. } \\
\text { T. A. } \\
\text { I. V. } \\
\text { B. U. } \\
\text { G. U. } \\
\text { M. A. } \\
\text { C. O. }\end{array}$ & $\begin{array}{l}21 \\
52 \\
40 \\
48 \\
73 \\
17 \\
45 \\
32\end{array}$ & $\begin{array}{l}2 \\
2 \\
2 \\
1 \\
3 \\
2 \\
1 \\
2\end{array}$ & $\begin{array}{c}\text { sec. } \\
56-59 \\
28-30 \\
30-32 \\
10-16.2 \\
12-12.2 \\
4.2-4.0\end{array}$ & $\begin{array}{c}\text { sec. } \\
57.5 \\
29 \\
31 \\
22 \\
12.06 \\
12.1 \\
6.5 \\
4.1\end{array}$ & $\begin{array}{l}2 \\
1 \\
2 \\
1 \\
1 \\
1 \\
1 \\
2\end{array}$ & $\begin{array}{c}\text { sec. } \\
27-30 \\
16-18\end{array}$ & $\begin{array}{l}\text { sec. } \\
23.5 \\
21.8 \\
17 \\
10 \\
6.2 \\
6.0 \\
2.5 \\
4.05\end{array}$ & $\begin{array}{c}59.1 \\
24.8 \\
45.1 \\
54.5 \\
48.4 \\
49.6 \\
61.5 \\
1\end{array}$ \\
\hline Mean & & & & 21.78 & & & 11.38 & 43.0 \\
\hline
\end{tabular}




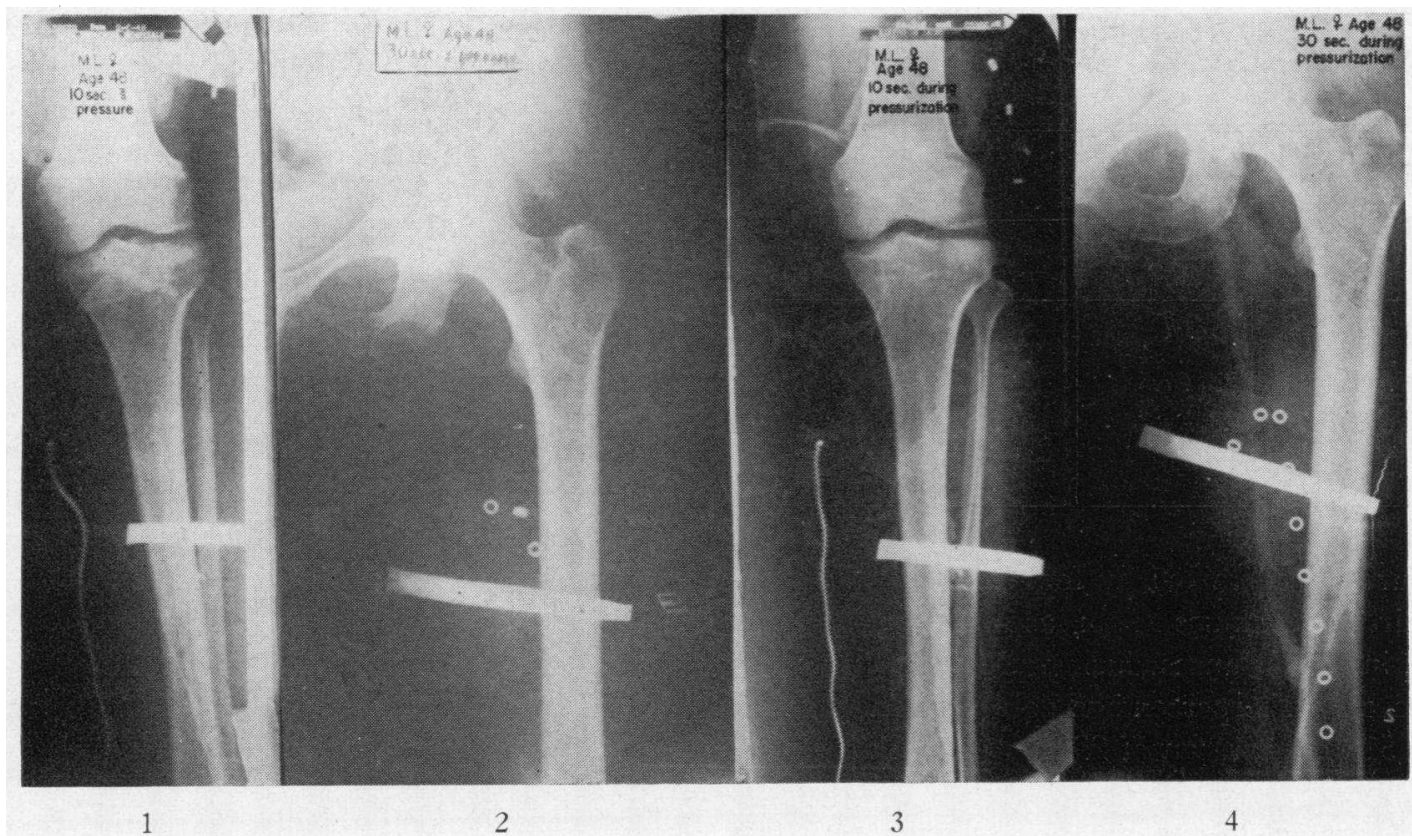

FIG. 1

Unretouched photographs of X-ray films taken to show the progress of an injected dose of Diodrast ( $4 \mathrm{cc}$.) before ( 1 and 2 ) and during ( 3 and 4 ) the application of $20 \mathrm{~mm}$. $\mathrm{Hg}$ pressure to the limb. Films 1 and 3 were taken 10 seconds, films 2 and 4, 30 seconds after injection. Dye may be seen just entering the distal femoral vein in film 2, while it has reached at least to the external iliac vein in film 4 .

major portion of the diodrast entered the deep venous system of the leg, the velocity of flow was unquestionably increased, in some instances to a striking degree.

Figure 1 illustrates unretouched photographs of serial roentgenograms of the dye in the deep veins of the calf and thigh of a 48-year-old female before and during the application of $20 \mathrm{~mm}$. $\mathrm{Hg}$ pressure. The calf films were taken 10 seconds and the thigh films 30 seconds after the injection. It is obvious that the injected diodrast moved at a markedly increased velocity when the limb was pressurized.

The results of such studies in five cases suitable for analysis are recorded in Table II. In each instance the application of pressure resulted in a definite increase in the linear velocity as determined by this technique. The mean increase in four cases was 45.4 per cent and the range 22 to 75 per cent while in the fifth case linear velocity was increased by 131 and 170 per cent in two tests.

Simultaneous observations in the control limb showed insignificant changes as compared with the
TABLE II

Effect of pressurization on the linear velocity of venous flow as measured from serial roentgenograms

\begin{tabular}{|c|c|c|c|c|}
\hline \multirow{2}{*}{ Patient } & \multirow{2}{*}{ Age } & \multicolumn{2}{|c|}{ Linear velocity, $\mathrm{cm} . / \mathrm{sec}$. } & \multirow{2}{*}{$\begin{array}{c}\text { Per cent } \\
\text { increase } \\
\text { in linear } \\
\text { velocity } \\
\text { during } \\
\text { pressurization }\end{array}$} \\
\hline & & $\begin{array}{c}\text { Before } \\
\text { pressurization }\end{array}$ & $\begin{array}{c}\text { During } \\
\text { pressurization }\end{array}$ & \\
\hline B. U. & 73 & 1.09 & 1.33 & 22 \\
\hline S. T. & 42 & $\begin{array}{l}1.4 \\
1.8\end{array}$ & $\begin{array}{l}3.8 \\
4.16\end{array}$ & 170 \\
\hline L. Y. & 48 & 1.2 & 1.8 & 50 \\
\hline J.P. & 44 & 4.5 & 5.7 & 49 \\
\hline M. E. & 55 & $\begin{array}{l}1.6 \\
2.0\end{array}$ & $\begin{array}{l}2.1 \\
3.5\end{array}$ & $\begin{array}{l}31 \\
75\end{array}$ \\
\hline
\end{tabular}

pressurized limb, while repetition of the test in the experimental limb in two of five cases after the release of pressure revealed the velocity of flow to have returned to pre-pressurization values.

\section{Circulation times}

\section{Foot-to-tongue}

Additional corroborative evidence of the acceleration of venous flow during the application of 
TABLE III

Effect of pressurization on the fool-to-tongue circulation time as measured by decholin sodium

\begin{tabular}{|c|c|c|c|c|}
\hline \multirow{2}{*}{ Patient } & \multirow{2}{*}{ Age } & \multicolumn{2}{|c|}{ Circulation time $(\mathrm{sec})}$. & \multirow{2}{*}{$\begin{array}{c}\text { Per cent } \\
\text { decrease } \\
\text { in circula- } \\
\text { tion time } \\
\text { during } \\
\text { pressurization }\end{array}$} \\
\hline & & Control & $\begin{array}{c}\text { During } \\
\text { pressurization }\end{array}$ & \\
\hline $\begin{array}{l}\text { T. A. } \\
\text { J. M. } \\
\text { R. H. } \\
\text { S. M. } \\
\text { H. E. } \\
\text { H. U. }\end{array}$ & $\begin{array}{l}24 \\
64 \\
72 \\
69 \\
67 \\
33\end{array}$ & $\begin{array}{l}37 \\
38.4 \\
27.5 \\
48.5 \\
87 \\
49\end{array}$ & $\begin{array}{l}18.2 \\
32 \\
17.5 \\
35.7 \\
62 \\
41\end{array}$ & $\begin{array}{l}51 \\
17 \\
36 \\
26 \\
29 \\
16\end{array}$ \\
\hline
\end{tabular}

pressure was obtained by foot-to-tongue (Decholin) circulation times in six cases. The circulation times in all instances during pressurization were decreased. The percentage decrease ranged from 16 to 51 with a mean of 29 per cent (Table III).

\section{The foot-to-femoral vein circulation time} as measured by Evans Blue Dye (T-1824).

The limb venous circulation time was estimated in two cases before and during the application of pressure, by measuring the concentration of injected dye in consecutive four-second samples from the femoral vein. In both cases the appearance time of the dye was markedly decreased during the application of pressure.

Figure 2 illustrates the results of this procedure in a 44-year-old male. It is noteworthy that the dye before pressurization was not present in the femoral vein until 20 seconds after injection at the

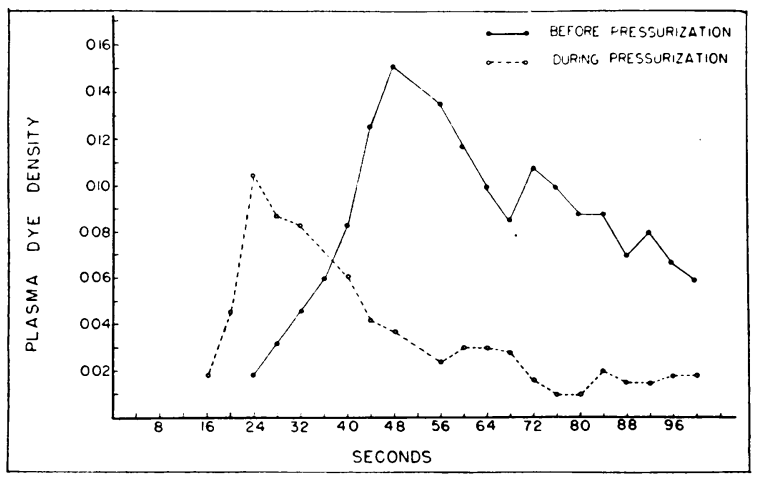

FIG. 2

Illustrates the effect of pressurization of the extremity on the appearance time and concentration curve of Evans Blue Dye (T-1824) in plasma samples obtained by continuous sampling from the femoral vein. foot whereas during pressurization it was present in 12 seconds. In addition, the shape of the concentration curves indicated that the veins were cleared of the injected dye in less time during the application of pressure. These findings indicate the velocity of venous flow was increased as measured by this technique.

\section{Additional observations}

In the course of this investigation the following collateral observations were made upon the size and shape of the leg veins and are reported because of their probable influence upon velocity of venous flow.

(a) In younger individuals the deep veins of the calf were noted usually to be narrow and straight as delineated by the contrast medium, which moved along rapidly in them. In older individuals, particularly those over 40 , the deep veins not infrequently exhibited saccular dilatations in which the diodrast tended to puddle. often remaining as long as 15 minutes.

(b) Veins well filled with diodrast as viewed in serial roentgenograms frequently exhibited a measurable decrease in diameter during the period of local compression along with the concomitant increase in linear velocity of flow.

(c) The application of pressure usually did not alter the distribution of the diodrast between the superficial and deep venous systems of the extremity, but rather accelerated the flow in both.

$(d)$ Increasing the pressure from 20 to $35 \mathrm{~mm}$. $\mathrm{Hg}$ did not cause a perceptible further increase in the velocity of venous flow.

(e) In six patients the velocity of venous flow as judged from the foot-to-tongue and foot-topharynx circulation times was similarly accelerated whether the source of local compression was an inflatable legging, an elastic stocking or a carefully applied elastic bandage.

(f) When diodrast was well visualized in the veins of the leg during pressurization it was usually present for a shorter total time than during the control period. This finding and the concentration curves of Evans Blue in femoral vein blood both suggest that the "venous emptying time" (13) was decreased by the application of pressure. 


\section{DISCUSSION}

It is recognized that large changes in the skin temperature of the digits may alter the circulation time, as demonstrated by Smith, Allen and Craig (11) and Stead and Kunkel (15). It is also obvious that a certain velocity is imparted to the test substances in the process of injection. In the present study diligent efforts were therefore made to control both factors. Furthermore, collateral studies of foot-to-tongue circulation times and simultaneous skin temperatures of the toes failed to reveal more than slight changes in the temperatures when the velocity of venous flow was increased during mild pressurization (16). The magnitude and uniformity of the velocity changes observed strongly suggest that the linear velocity of venous flow in the leg veins is increased by the local application of pressure.

Ochsner has recommended compression of the limbs by elastic bandages as a prophylactic measure against phlebothrombosis and pulmonary embolism in surgical patients, on the supposition that compression of the superficial veins would drive more blood through the deep vessels and thus accelerate flow in these channels (17). In the present study the application of pressures of 20 to $35 \mathrm{~mm}$. $\mathrm{Hg}$ seldom altered the distribution of the injected diodrast in the deep and superficial veins but did accelerate the flow in both.

It has been reported previously from this laboratory that the local application of pressures of as little as $30 \mathrm{~mm}$. $\mathrm{Hg}$ decreases the volume of blood flow into the limbs (18). The present experiments demonstrate that in spite of the decrease in volume of arterial blood flow into the limbs there is simultaneously during mild pressurization an increase in linear velocity of venous flow from the limbs. The observation that the veins appear smaller during compression suggests that the observed acceleratory effect is due primarily to a disproportionately greater decrease in cross-sectional area of the venous bed than the decrease in the volume of blood flow into the limbs during such compression. It is significant that marked increases in the linear velocity of venous flow could be produced by the local application of pressures of as little as $20 \mathrm{~mm}$. Hg pressure. Since this pressure (in contrast to higher pressures) causes only slight decrease in inflow (18), it is probably near the optimum pressure for the maximum acceleratory effect. The possible therapeutic applications of this principle are now under study in this clinic.

\section{SUMMARY AND CONCLCSIONS}

1. The application of local pressure of 20 to 35 $\mathrm{mm} . \mathrm{Hg}$ to the lower extremity of human subjects increased the velocity of venous flow-as measured by fluoroscopy, serial roentgenograms, foot-totongue circulation times, and limb venous circulation times.

2. Pressures of $20 \mathrm{~mm}$. $\mathrm{Hg}$ applied to the lower extremities of man significantly increased the linear velocity of flow in the deep veins, but did not alter significantly the distribution of injected diodrast between the superficial and deep venous channels.

3. It is suggested that the mechanism of the increase in linear velocity of venous flow during local compression is the concomitant decrease in the total cross-sectional area of the venous beds.

The authors are genuinely indebted to Doctors George Levene and Harry Lerner and to Miss Anne Lally and the X-ray technicians of the Department of Radiology of the Massachusetts Memorial Hospitals for cooperation and aid in carrying out the radiographic techniques employed in this study.

\section{BIBLIOGRAPHY}

1. Greville, T. N. E., United States Life Tables and Actuarial Tables, 1931-1941. United States Dept. of Commerce; Gov. Print. Off., Washington, D. C., 1946.

2. McCartney, J. S., Postoperative pulmonary embolism. Surg., 1945, 17, 191.

3. Neuhof, H., Venous Thrombosis and Pulmonary Embolism. Grune \& Stratton, New York, 1948.

4. Morton, J. J., Mahoney, E. B., and Mider, G. B., Evaluation of pulmonary embolism following intravascular venous thrombosis. Ann. Surg., 1947, 125, 590 .

5. Virchow, R., Gesammelte Abhandlungen zur Wissenschaftlichen Medicin. Meidinger Sohn and Comp., Frankfort 1856, pp. 57-147, 219-732.

6. Rössle; R., Ùber die Bedeutung und die Eutstchung der Wadenvenenthrombosen. Virchows Arch. $f$. path. Anat., 1937, 300, 180.

7. Neumann, R., Ursprungszentiem und Eutwicklungsformen der Bein-thrombose. Virchows Arch. f. - path. Anat., 1938, 301, 708.

8. Homans, J., Thrombosis of deep veins of lower leg, causing pulmonary embolism. New England J. Med., 1934, 211, 993. 
9. Hunter, W. C., Sneeden, V. D., Robertson, T. D., and Snyder, G. A. C., Thrombosis of deep veins of $\mathrm{leg}$; its clinical significance as exemplified in 351 autopsies. Arch. Int. Med., 1941, 68, 1.

10. Bauer, G., Venographic study of thrombo-embolic problems. Acta chir. Scandinav., 1940, 84, Supp. 61, pp. 1-75.

11. Smith, L. A., Allen, E. V., and Craig, W. M., Time required for blood to flow from arm and from foot of man to carotid sinuses; effect of temperature, exercise, increased intramuscular tension, elevation of limbs and sympathectomy. Arch. Surg., 1940, 41, 1366.

12. Smith, L. A., and Allen, E. V., Circulation time from foot to carotid sinus and from arm to carotid sinus of man; effects of operation and of administration of thyroid gland; postoperative phlebitis and pulmonary embolism. Arch. Surg., 1940, 41, 1377.
13. Frimann-Dahl, J. Von, Postoperative Röntgenuntersuchungen; Diaphragmabewegungen und der postoperative Venenstrom; postoperative Lungenembolien. Acta chir. Scandinav., 1935, 76, Supp. 36.

14. Eberth, C. J., and Schimmelbush, C., Die Thrombose nach Versuchen U. Liechenbefunden. Stuttgart. 1888.

15. Stead, E. A., Jr., and Kunkel, P., Influence of peripheral circulation in upper extremity on circulation time as measured by sodium cyanide method. Am. J. Med. Sc., 1939, 198, 49.

16. Stanton, J. R. Unpublished data.

17. Ochsner, A., Venous thrombosis. J. A. M. A., 1946, $132,827$.

18. Halperin, M. H., Friedland, C. K., and Wilkins, R. W., The effect of local compression upon blood flow in the extremities of man. Am. Heart J., 1948, 35, 221. 